\title{
REMOVING BARRIERS, INTEGRATING RESEARCH, SPREADING EXCELLENCE: THE EUROPEAN SATELLITE COMMUNICATIONS NETWORK OF EXCELLENCE "SATNEX"
}

\author{
Markus Werner, ${ }^{1}$ Anton Donner, ${ }^{1}$ Michel Bousquet, ${ }^{2}$ Giovanni E. Corazza, ${ }^{3}$ \\ Barry Evans, ${ }^{4}$ Y Fun $\mathrm{Hu},{ }^{5}$ Erich Lutz, ${ }^{1}$ Gérard Maral,${ }^{6}$ Robert Rumeau ${ }^{7}$ \\ and Ray E. Sheriff ${ }^{5}$ \\ ${ }^{1}$ Institute of Communications and Navigation, German Aerospace Center (DLR), Weßling, \\ Germany, ${ }^{2}$ Le Départment Systèmes Electroniques Photoniques et Télécoms, SUPAERO, \\ Toulouse, France, ${ }^{3}$ DEIS/ARCES - University of Bologna, Bologna, Italy, ${ }^{4}$ Centre \\ for Communication Systems Research, University of Surrey, Surrey, UK, ${ }^{5}$ School \\ of Engineering, Design and Technology, University of Bradford, West Yorkshire, UK, \\ ${ }^{6}$ GET/Ecole Nationale Supérieure des Télécommunications (ENST), Toulouse, France, \\ ${ }^{7}$ Centre National d'Etudes Spatiales (CNES), Toulouse, France
}

\begin{abstract}
Within the recently launched 6th research framework programme of the European Commission, 21 major players in satellite communications research have joined forces to implement the European satellite communications network of excellence (SatNEx). The primary goal of SatNEx is to achieve long-lasting integration of the European research in satellite communication. This paper discusses the motivation for implementation of the network and highlights the SatNEx mission and key objectives. A top-level overview is provided including a description of the consortium and the joint programme of activities (JPA). Finally, an update of ongoing work is presented.
\end{abstract}

Keywords: Information Society Technologies (IST), European sixth research framework programme (FP6), network of excellence (NoE), SatNEx

\section{Introduction}

Within the broad field of communications, satellites are successfully used for broadcast, mobile, and broadband communication. They play an important role for the competitiveness of the European Union (EU) in the field of communication technologies and support the autonomy of 
Europe in space matters. Europe has always retained a major presence in both manufacturing satellites (Alcatel, EADS/Astrium, Alenia Aerospazio, ...) as well as launching and operating satellites (Arianespace, ...) and providing satellite services (SES Global, Eutelsat, Inmarsat, ...).

Satellite communications has been an area in the satellite field that has been commercially successful so far and this has been helped and pump primed by the research and development (R\&D) programs of the European Space Agency (ESA) and by the EU framework programmes. European research carried out a large number of successful activities in satellite communications (ESA and EU projects, European co-operation in the field of scientific and technical research (COST) actions ${ }^{1}$, the task force on advanced satellite mobile systems (ASMS-TF) ${ }^{2}$, etc.). Their efforts have made it possible to create a solid industrial base and to give Europe recognized capabilities and capacities. However, these actions show only limited collaboration and lack of critical mass. Compared to the leading power in space, the United States, where the use of space systems is not only a technological instrument, but a strategic, political and economic instrument guaranteeing the American leadership, Europe in the past has shown only limited interest in developing a common European approach to put its resources together and cooperate intensively even without the support from ESA.

In latter years, satellite communications has been viewed as a mature area that is more the responsibility of industry and commerce and less that of the $R \& D$ agencies. This has resulted in reduced staff support for $\mathrm{R} \& \mathrm{D}$ in the area in preference to the science and navigation/positioning areas. At the same time we have seen a rationalization of the industrial business due to economic pressures manifested in mergers of the large industrial companies both within Europe and globally.

\section{SatNEx Motivation and Mission Inner-European Fragmentation}

With varying levels of financial support, industrial countries within the EU have established their own national space R\&D programs (e.g., France, Italy, Germany and the UK) which reflect both their support for national industries as well as political priorities for space. Again within these areas the role of communications vis-a-vis science, remote sensing and positioning has been small. Most of the R\&D has been technology

\footnotetext{
${ }^{1}$ http://cost. cordis.lu

${ }^{2}$ http://www . asms-tf .org
} 
push driven, rather than applications pull. Industry has focused on the next satellite platform in a fairly conservative and incremental fashion even to the exclusion of applications. The satellite industry also has been very late into the standards arena preferring to provide proprietary solutions and this is in stark contrast to both the fixed and mobile terrestrial operations.

Within the European academic and research institutions, there has also been little critical mass concentration on satellite communications. Expertise is largely spread and where it exists it is not entirely focused on satellite communications but more generally applicable with satellites being merely one application. There is no single satellite communications research institute existing in Europe at this time (except ESA).

\section{Role of SatNEx}

A major aim of SatNEx is to rectify this fragmentation by bringing European research in satellite communications together in a durable manner. The creation of this centre via the network will enable critical mass and access to a range of expertise across Europe. We intend to make this available to staff and students moving between institutions and using specialists' facilities of these institutions as well as research students who can spend periods of time in any institution of the network. Most importantly we intend to produce a common platform with delivery via satellite for all partners who will use this as a means for integrated research, teaching and training - the SatNEx platform. Research in satellite communications across Europe needs a long-term vision from which to develop a technology and service roadmap that will drive the longer-term research program. SatNEx aims to produce in collaboration with industry this vision and to maintain and update it during the lifetime of the project. Such a detailed vision has already been produced for mobile communications and we intend to link with the wireless world research forum (WWRF) in producing the satellite vision. We will need to create this vision in the fixed broadband, mobile, broadcast and navigation/positioning areas. SatNEx will link with FP6 integrated projects (IPs) and specific targeted research projects (STREPs) in the area of satellite communications and provide input to these projects. It will however look further ahead to a longer-term research mission within its integrated research program.

SatNEx has been designed as a joint venture between institutions that have as their mandate the production of new knowledge and the transfer of this knowledge to industry and to society at large. The network has a specific focus in satellite communications, which has been recognized as a 
strategic field of knowledge for Europe, both in terms of its commercial return and, perhaps more importantly, in terms of its impact on the continent's security and the connectivity of all countries, particularly the new enlargement countries.

At the same time, satellite industry is living through very difficult times, due to a general market regression and to some recent failures that have affected the possibility to receive adequate loans and investments from banks. As a consequence, industry is looking only at short term results and revenues, which is understandable but also very risky, because the gap with respect to US technology that we have today could become unrecoverably large in the near future, unless some far looking political decisions are made and sustained with concrete actions.

An important objective of SatNEx is knowledge transfer to both the research community at large as well as the existing satellite industry. Knowledge transfer will take place via training courses, conferences and workshops and skills development into existing business as well as via specific briefings to industry.

In such a contingency, the role of universities and research institutions grows well beyond the niche of lightly-controlled basic research, to become that of a central and instrumental strategic incubator for the development of new concepts and ideas that, once transferred to the industry, will enable to compete and possibly to take the lead in this business of fundamental importance. Universities and research institutes can play a crucial role in supporting European industry, using SatNEx as a structure facilitating the identification of needs, generation of new ideas and concepts, coordination of activities, and development of new knowledge in the strategic field of satellite communications.

\section{SatNEx Mission and Key Objectives}

The prime objective of SatNEx, to overcome fragmentation of European satellite communications research through the integration of partners, cannot be dissociated from the production of new knowledge. This would defeat the main benefit that SatNEx could bring to Europe. Limiting all efforts to integrating partners, relocating staff, developing common simulators, reorganizing the structure, and filling gaps in the research portfolio would fully comply to the criteria for NoE acceptance. But this would not achieve the critical objective of producing the evolutionary or revolutionary ideas that may serve to shift the satellite communications paradigm in favor of the European industry.

Integration is a very sensible objective, but it must be finalized to the achievement of breakthrough ideas. In this sense, partners integration 
may take on several forms. It could entail joint activities, it could encompass competing activities, it might involve growing one-another-up, it could include complementary activities. However, integration is useful if, and only if, new knowledge is produced as a result. Otherwise we would not have served for the benefit of our continent in the field of satellite communications. For sure, this type of reasoning may not apply to other fields where Europe is already in the lead, and the major problem is fragmentation of resources.

In order to measure the impact of new knowledge, classic instruments are more than applicable and perfectly adequate: patents, publications in journals, contributions to conferences, highly qualified training, exploitation of intellectual property rights. SatNEx will use its integrated means (hardware/software tools, platforms, exchange programs, etc) to enable the highest level of research and production of new knowledge. SatNEx will do this with the resources available, under the governance structure foreseen, for the objectives identified. Definitely, this will be well-spent funding from the European Commission (EC).

Attention should finally be given to the new White Paper on Space of the European Commission, entitled "Space: a new European frontier for an expanding Union - an action plan for implementing the European Space policy". The political actions that are foreseen in this document are very encouraging. The SatNEx NoE appears to be perfectly in line with the European strategy for space.

\section{SatNEx Overview}

\section{Consortium}

In the SatNEx NoE, 21 partners from 9 European countries, as listed in Table 1, join their research forces and bring in a wide-spread expertise for integration, ongoing joint research and spreading of excellence. The consortium is made up by a well balanced mix of higher education (HE) institutions and research organisations (RES), where two of the latter also have the small \& medium enterprise (SME) status. Industry partners are integrated into SatNEx via the Advisory Board (see Fig. 1). SatNEx is coordinated and managed by the Institute of Communications and Navigation of the German Aerospace Center (DLR).

Table 1: Overview of the SatNEx consortium.

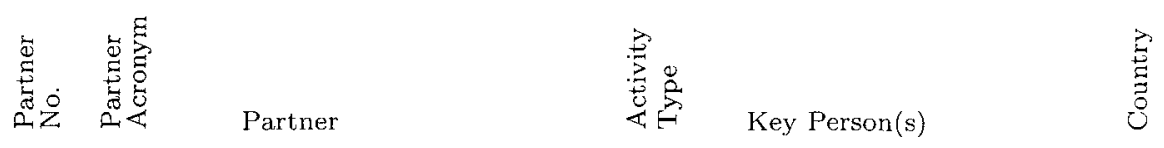




\begin{tabular}{|c|c|c|c|c|c|}
\hline 1 & DLR & $\begin{array}{l}\text { Deutsches Zentrum für } \\
\text { Luft- und Raumfahrt e.V. }\end{array}$ & RES & $\begin{array}{l}\text { Prof. Erich Lutz } \\
\text { Dr. Markus Werner }\end{array}$ & $\mathrm{D}$ \\
\hline 2 & AUTh & $\begin{array}{l}\text { Aristotle University of } \\
\text { Thessaloniki }\end{array}$ & $\mathrm{HE}$ & Prof. Niovi Pavlidou & GR \\
\hline 3 & BRU & University of Bradford & $\mathrm{HE}$ & $\begin{array}{l}\text { Prof. Ray Sheriff } \\
\text { Dr. Fun Hu }\end{array}$ & UK \\
\hline 4 & BUTE & $\begin{array}{l}\text { Budapest University of } \\
\text { Technology and Eco- } \\
\text { nomics }\end{array}$ & $\mathrm{HE}$ & Prof. István Frigyes & $\mathrm{HU}$ \\
\hline 5 & CNES & $\begin{array}{l}\text { Centre National d'Etudes } \\
\text { Spatiales }\end{array}$ & RES & Robert Rumeau & $\mathrm{F}$ \\
\hline 6 & CNIT & $\begin{array}{l}\text { Consorzio Nazionale } \\
\text { Interuniversitario per le } \\
\text { Telecomunicazioni }\end{array}$ & $\begin{array}{l}\text { RES/ } \\
\text { SME }\end{array}$ & $\begin{array}{l}\text { Prof. Guido Albertengo } \\
\text { Prof. Giuliano Benelli } \\
\text { Prof. Franco Davoli } \\
\text { Prof. Enrico Del Re } \\
\text { Prof. Sergio Palazzo }\end{array}$ & I \\
\hline 7 & FhI & $\begin{array}{l}\text { Fraunhofer Gesellschaft } \\
\text { zur Förderung der Ange- } \\
\text { wandten Forschung e.V. }\end{array}$ & RES & $\begin{array}{l}\text { Dr. Thomas Luckenbach } \\
\text { Prof. Karl Jonas }\end{array}$ & $\mathrm{D}$ \\
\hline 8 & GET & $\begin{array}{l}\text { Groupe des Ecoles des } \\
\text { Télécommunications }\end{array}$ & $\mathrm{HE}$ & Prof. Gérard Maral & $F$ \\
\hline 9 & ICCS & $\begin{array}{l}\text { Institute of Communi- } \\
\text { cation and Computer } \\
\text { Systems of NTUA }\end{array}$ & RES & $\begin{array}{l}\text { Prof. Nikolaos Uzunoglu } \\
\text { Dr. Philip Constantinou }\end{array}$ & GR. \\
\hline 10 & ISARS & $\begin{array}{l}\text { National Observatory of } \\
\text { Athens }\end{array}$ & RES & $\begin{array}{l}\text { Prof. Takis } \\
\text { Mathiopoulos }\end{array}$ & GR \\
\hline 11 & ISTI & $\begin{array}{l}\text { Istituto di Scienze e } \\
\text { Tecnologia dell'Infor- } \\
\text { mazione "Alessandro } \\
\text { Faedo" }\end{array}$ & $\begin{array}{l}\text { RES/ } \\
\text { SME }\end{array}$ & Dr. Erina Ferro & I \\
\hline 12 & JSI & Jožef Stefan Institute & RES & Prof. Gorazd Kandus & SLO \\
\hline 13 & RWTH & $\begin{array}{l}\text { Rheinisch-Westfälische } \\
\text { Technische Hochschule } \\
\text { Aachen }\end{array}$ & $\mathrm{HE}$ & $\begin{array}{l}\text { Dr. Carl-Herbert } \\
\text { Rokitansky }\end{array}$ & $\mathrm{D}$ \\
\hline 14 & $\begin{array}{l}\text { TéSA/ } \\
\text { ONERA }\end{array}$ & $\begin{array}{l}\text { Office National d'Etudes } \\
\text { et de Recherches Aéro- } \\
\text { spatiales }\end{array}$ & RES & Prof. Michel Bousquet & $\mathrm{F}$ \\
\hline 15 & TUG & $\begin{array}{l}\text { Institut für Kommunika- } \\
\text { tionsnetze und Satelliten- } \\
\text { kommunikation, TU Graz }\end{array}$ & $\mathrm{HE}$ & Prof. Otto Koudelka & A \\
\hline 16 & UCIIIM & $\begin{array}{l}\text { Universidad Carlos III de } \\
\text { Madrid }\end{array}$ & $\mathrm{HE}$ & $\begin{array}{l}\text { Dr. Francisco Javier } \\
\text { González Serrano } \\
\text { Dr. María Ángeles } \\
\text { Vázquez Castro }\end{array}$ & $\mathrm{E}$ \\
\hline 17 & Unis & The University of Surrey & $\mathrm{HE}$ & Prof. Barry Evans & UK \\
\hline 18 & UoA & $\begin{array}{l}\text { The University Court of } \\
\text { the University of Aber- } \\
\text { deen }\end{array}$ & $\mathrm{HE}$ & Dr. Godred Fairhurst & UK \\
\hline 19 & UoB & $\begin{array}{l}\text { Dipartimento di Elettro- } \\
\text { nica, Informatica e Sis- } \\
\text { temistica, Alma Mater } \\
\text { Studiorum, Università di } \\
\text { Bologna }\end{array}$ & $\mathrm{HE}$ & $\begin{array}{l}\text { Prof. Giovanni E. } \\
\text { Corazza }\end{array}$ & I \\
\hline 20 & UToV & $\begin{array}{l}\text { Università Degli Studi Di } \\
\text { Roma "Tor Vergata" }\end{array}$ & $\mathrm{HE}$ & $\begin{array}{l}\text { Prof. Nicola } \\
\text { Blefari-Melazzi } \\
\text { Prof. Francesco Vatalaro }\end{array}$ & I \\
\hline
\end{tabular}


21 UVI Universidad De Vigo

HE Prof. Francisco Javier

E González Castaño

Collectively the SatNEx partners have the necessary critical mass of expertise and resources to successfully carry out the joint programme of activities (JPA) which is outlined in the following.

\section{Joint Programme of Activities (JPA)}

Figure 1 shows the work package (WP), breakdown structure of the JPA:

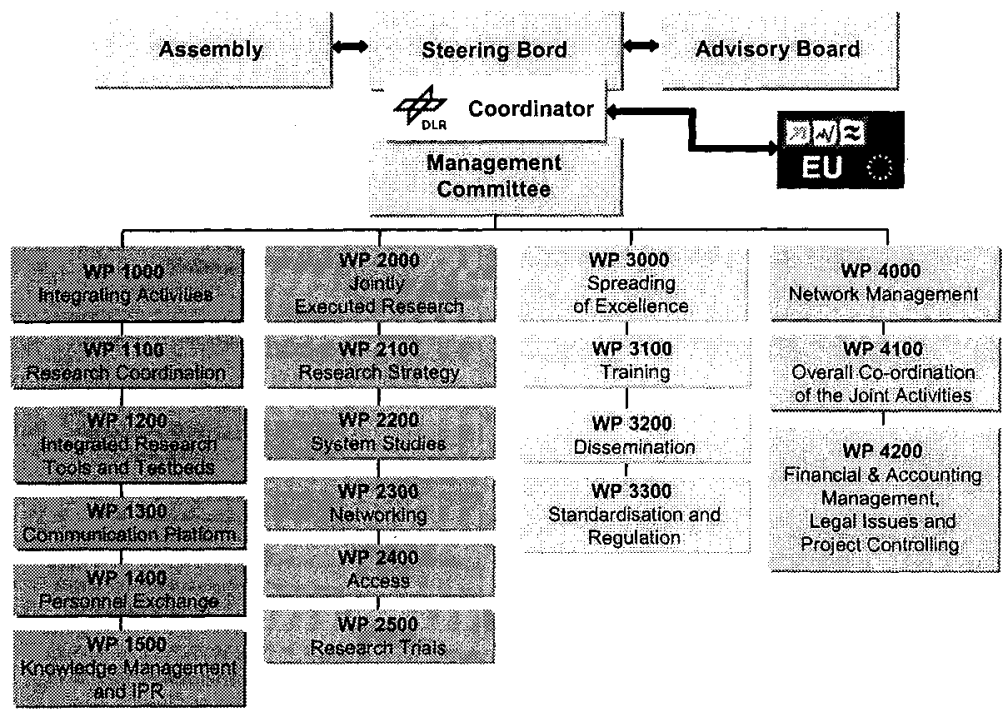

Figure 1: Breakdown of the SatNEx organisational structure and the joint programm of activities (JPA).

- The Integrating Activities (WP 1000) support the jointly executed research (JER) (WP 2000) by co-ordinating the participants' research (WP 1100), integrating research tools and testbeds (WP 1200), providing a communication and collaboration platform (WP 1300), organising the exchange of students and personnel (WP 1400), and performing integrated management of knowledge and intellectual property (WP 1500).

- The JER activities (WP 2000) produces new knowledge and supports WP 1000 by developing common research tools and testbeds, 
proposing suitable cases for personnel exchange, and providing new knowledge and expertise.

- Finally, WP 3000 primarily aims at the spreading of excellence to Europe beyond SatNEx. This activity provides training opportunities, disseminates information and transfers knowledge, influences standardisation and regulation, and enhances public awareness of the benefits of satellite communications.

The activities and workpackages of the JPA are interconnected by a dense mesh of integrating relationships as illustrated in Fig. 2. On top of the support from integrating activities (WP 1000), there is a strong connection between the jointly executed research (JER) (WP 2000) and the spreading of excellence: WP 2000 produces new knowledge and intellectual property which gives input for standardisation and regulation (WP 3300). Vice versa, WP 3000 provides information from standardisation and regulation bodies to WP 2000. Moreover, WP 1000 supports the spreading of excellence (WP 3000) by offering the communication and collaboration platform.

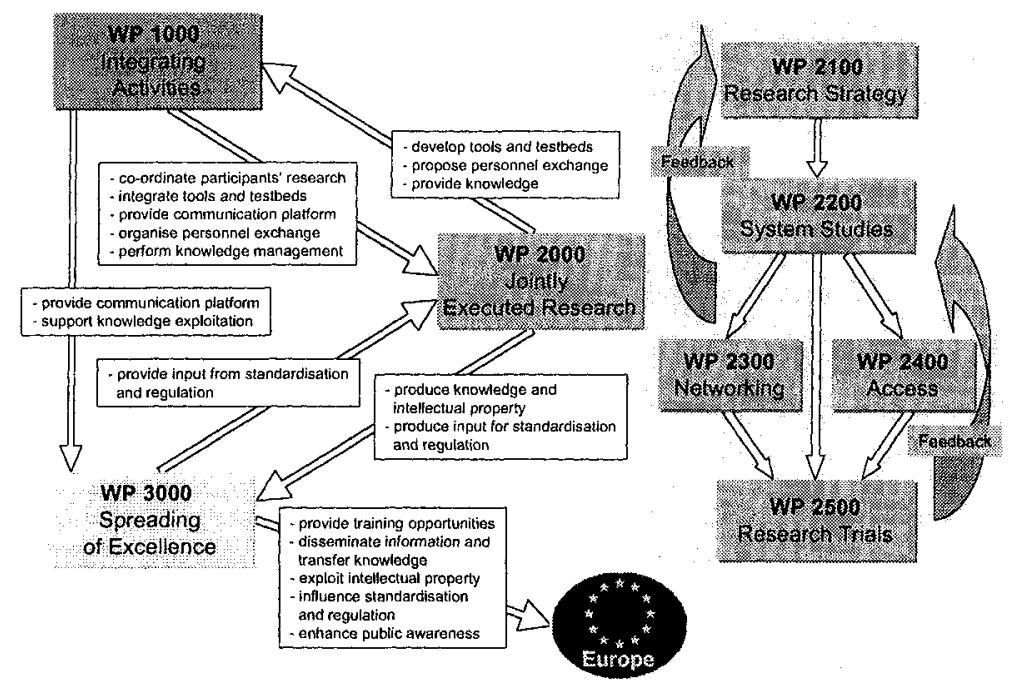

Figure 2: Interdependencies between JPA elements.

Efficient management and implementation of JER (WP 2000) is insured thanks to strong relationships between the workpackages in the WP 2000 activity: the research strategy and visions (WP 2100) drive 
the system studies (WP 2200) which in turn have influence on the research in networking (WP 2300) and access (WP 2400) as well as on the research trials (WP 2500).

The philosophy underlying the SatNEx approach consists in the selection of focused actions within the broad framework described by the overall JPA, in order to capitalize on the expertise that are present within the network and to make sure that the integration is effective and durable. These focused actions are to be carried out jointly by the partners, and are identified as joint activitys (JAs). They include research, integration, and disseminating activities. The research activity, in particular, focuses on knowledge gaps that may be present within the network and on extending the knowledge which is brought in at the project start-up by the various partners. The emphasis will be on the challenge to existing concepts and ideas, in the never ending search for improvements and breakthroughs, which can only be achieved by leaving the field open to exploratory research activities.

\section{Joint Activities (JAs)}

The implementation of the SatNEx NoE requires the definition of a number of specific and more concrete activities, both for thematic planning and work organisation in the group of partners and for the financial planning. In the following we explain the concept of SatNEx joint activitys (JAs).

The JAs are the fundamental unit in the implementation of the SatNEx JPA. A SatNEx JA is defined as a set of coherent activities, cost elements and procedures to achieve a specified objective within an associated time frame. A JA is jointly performed by a team of SatNEx partners, a joint activity team (JAT). Each JA must be focused on a relevant part of the JPA

It is explicitly stated that the WP structure (see Fig. 1) is the organisational framework of SatNEx, setting out the scope of and also the responsibilities within the project. Whereas, the JAs are the new way/methods of putting the SatNEx objectives into practice. They are the elements specifying how the work is performed.

The JA concept does not replace the classical WPs, rather it provides a new approach that is more suitable to the key NoE philosophy and elements and - not less important - will allow to bridge some gap between

- the classical (vertical) WP breakdown structure, and

- the (horizontal) NoE elements: integration, joint research, spreading of excellence. 
Table 2 gives an overview of JAs which have been launched at SatNEx kick-off. The list does not yet completely cover the WP 2000 breakdown. WP 3100 and WP 3300 are intentionally not covered by JAs. This is due to the fact that all partners participate in these WPs and thus no special JAs are necessary for them.

Table 2: Ongoing SatNEx joint activities.

$\begin{array}{ll}\text { JA-1000 } & \text { Removing Barriers to Integration } \\ \text { JA-1100 } & \text { Collective Research Portfolio } \\ \text { JA-1300 } & \text { Networking Means for Integration and Dissemination } \\ \text { JA-2100 } & \text { Research Strategy and Visions } \\ \text { JA-2230 } & \text { High Altitude Platform System Architecture for Fixed and } \\ & \text { Mobile Communications } \\ \text { JA-2300 } & \text { Network Performance and Protocols } \\ \text { JA-2330 } & \text { Routing, Traffic Engineering and On-board Switching } \\ \text { JA-2350 } & \text { Network Security and Network Management } \\ \text { JA-2410 } & \text { Channel Modelling and Propagation Impairments Simulation } \\ \text { JA-2420 } & \text { Flexible Waveforms } \\ \text { JA-2430 } & \text { IP QoS and Radio Resource Management with Cross-Layer } \\ & \text { Approach } \\ \text { JA-3200 } & \text { Conferences on SatComs }\end{array}$

So far all JATs have finished their "open book phase", which is a key requirement for future partner consolidation. Right now most of them start with JER.

\section{Conclusion}

The recently started European satellite communications network of excellence (SatNEx) has been presented. The primary goal of SatNEx is to achieve long-lasting integration of the European research in satellite communication and to develop a common base of knowledge, thus contributing to the realization of the European research area. Updated information about SatNEx can be found in http://www. satnex.org.

\section{Acknowledgements}

Part of this work is supported by the EC in the framework of the IST programme under the project SatNEx (IST-507052). The authors are solely responsible for this paper and it does not necessarily represent the opinion of the EC. The Commission and the authors do not accept any responsibility for the use of any data in this paper. 